\title{
Juego de tronos: adaptación del modelo RTTP (reacting to the past) para la enseñanza de la literatura
}

(Game of Thrones: Adapting the RTTP Model to the Teaching of Literature)

Aurelio Iván Guerra FéLIX ${ }^{\circledR}$, Universidad de Sonora, Sonora, México

Volumen 1, Número 1

Edición especial. Febrero de 2016

p. $179-199$

Este número se publicó el 5 de febrero de 2016

Artículo recibido: 9 de marzo de 2015

Artículo aprobado: 18 de noviembre de 2015

ISSN: 2448-5942, doi: https://doi.org/10.36799/el.v1i1.28

Citar este artículo como:

Guerra Félix, A. I. (2016). Juego de tronos: adaptación del modelo RTTP (reacting to the past) para la enseñanza de la

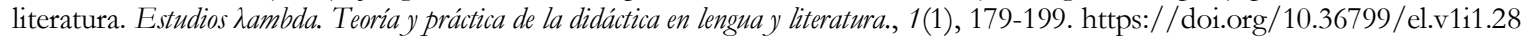

Derechos de autor: El autor o autores conservan en todo momento sus derechos morales y patrimoniales sobre la obra; la obra no se puede alterar, transformar o ampliar; siempre debe reconocerse la autoría del documento

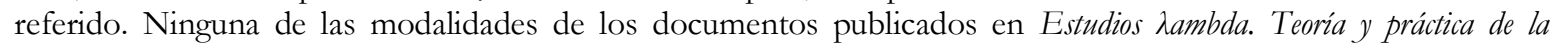
didáctica en lengua y literatura tienen fines comerciales de naturaleza alguna.

Los contenidos de este artículo están bajo la licencia de Creative Commons Atribución No Comercial- Sin Derivadas 4.0 Internacional @) $(\Theta \Theta$ 


\title{
Juego de tronos: adaptación del modelo RTTP (reacting to the past) para la enseñanza de la literatura
}

\author{
(Game of Thrones: Adapting the RTTP Model to the Teaching of Literature)
}

AURELIO IVÁN GUERRA FÉLIX ${ }^{1}$

\section{RESUMEN}

El RTTP (reacting to the past por sus siglas en inglés) es un modelo o sistema de enseñanza-aprendizaje que se basa en los juegos de roles. Este modelo o sistema ha sido empleado por decenas de profesores en diversas universidades norteamericanas con considerable éxito, según los testimonios que se encuentran disponibles en libros y videos en internet. En este trabajo me propongo exponer la adaptación de este modelo para la enseñanza de la literatura, tomando como caso la aplicación que se realizó de un juego original siguiendo este sistema en la materia de literatura española medieval (Literatura Española I) en la Licenciatura en Literaturas Hispánicas de la Universidad de Sonora durante el mes de octubre del 2014. En este trabajo se explica en qué consiste el RTTP, cuáles son sus atributos, en qué consistió la actividad del Juego de tronos, qué resultados se obtuvieron, así como una conclusión en la que se proponen nuevas rutas para su aplicación en los estudios literarios.

PALABRAS CLAVE: RTTP, juegos de roles, experiencias didácticas, didáctica de la literatura española medieval, Juego de tronos.

\begin{abstract}
RTTP (reacting to the past) is a role-play based learning model. This model or system has been successfully implemented in various North American universities. According to print and video testimonials, this method has proved to be very useful in helping students learn history and develop other capabilities through engagement with the main ideas and actions of the past. In this essay I present an adaptation of this model to the teaching of literature. During the month of October 2014, the model was applied to the study of Medieval Spanish Literature in a game dealing with Alfonso X and his ambitions of becoming Holy Roman Emperor. This text explains RTTP briefly and then proceeds to discuss some of the attributes of this model. It includes a description of our activity termed 'The deed of empire: game of thrones' with reflections on the results obtained. I also include proposals for further adaptation of this model in the teaching of literature.
\end{abstract}

KEYWORDS: RTTP (Reacting to the past) RPG (Role-playing game), didactic experiences, didactics of Medieval Spanish Literature, Game of Thrones.

\footnotetext{
1 Profesor de tiempo completo en la Licenciatura en Literaturas Hispánicas del Departamento de Letras y Lingüística de la Universidad de Sonora. Maestría en Literatura Hispanoamericana y Doctor en Humanidades. ivan.guerra@gmail.com
}

Artículo recibido: 9 de marzo de 2015

Artículo enviado a corrección: 25 de septiembre de 2015

Aprobado: 18 de noviembre de 2015 


\section{INTRODUCCIÓN}

Reacting to the past (RTTP) es un modelo de enseñanza-aprendizaje que se basa en el juego de roles. Se trata de un modelo que ha sido desarrollado por varios profesores que se han agrupado en una asociación que abarca un consorcio de universidades norteamericanas. Por más de una década profesores de este consorcio han implementado con considerable éxito este modelo didáctico creando dinámicas llamadas de 'interacción con el pasado’ que se han puesto en práctica en varias universidades. Como resultado de lo anterior se han generado manuales para la aplicación de este modelo, así como libros de texto de interacciones específicas que ya han sido llevadas a la práctica. El gran mérito de este modelo, según se ha recogido en la experiencia de quienes lo hemos aplicado, es que logra que los estudiantes se involucren profundamente con los contenidos de sus materias. Quienes han participado y compartido su experiencia coinciden en que el aprendizaje se convierte en una diversión y, en ocasiones, hasta en una obsesión. También se observa, al analizar los beneficios de la aplicación de este modelo, su importancia en el desarrollo de habilidades y actitudes que no se incorporarían en el aula como parte del proceso de la enseñanza empleando métodos tradicionales.

Dado que el sistema RTTP es tan ampliamente recomendado, decidí hacer la adaptación de este modelo para la enseñanza de la literatura en la asignatura de Literatura Española I en la Licenciatura en Literaturas Hispánicas de la Universidad de Sonora. En este trabajo se presenta la adaptación de ese modelo para el análisis en el aula de un momento central del desarrollo e invención de la prosa castellana que sucedió durante el siglo XIII. Primero se explicará el contexto de la materia y por qué decidí hacer esta adaptación para estudiar ese momento histórico estudiado. Después trataré de explicar en qué consiste el juego y cuáles son algunos de sus procesos y recursos utilizados. Una vez establecidas las bases, comentaré sobre la adaptación específica del juego en nuestra materia y terminaré señalando los beneficios de este modelo en los estudios literarios así como posibles adaptaciones adicionales. 


\section{EL CONTEXTO}

La cultura y la historia de la Edad Media han sido motivo de interés y curiosidad artística para un amplio público desde el medievalismo romántico hasta nuestros días (Gerrard 5). Usualmente aquello que hoy en día atrae a las personas a la ficción basada en la Edad Media es algo distinto a lo que se encuentra en los textos de aquella época y es distinto también al contenido medieval que atraía al hombre romántico. Exclamaba Teófilo Gautier en 1835:

¡Cómo me han echado a perder mi Edad Media, tan delicada y colorida [. . .]! No habéis visto de la Edad Media más que la cáscara. Ni siquiera habéis adivinado el alma de la Edad Media, porque la sangre no circula por la piel con que habéis revestido vuestros fantasmas. No hay corazón dentro de esas corazas de acero [. . .]. De modo que, ¡abajo la Edad Media tal como nos la han hecho ver los intrigantes! (Gautier 15)

Con lo cual da a entender que aquello que sus contemporáneos representaban en la ficción como medieval, no correspondía con lo que él consideraba la verdadera Edad Media.

La Edad Media ha despertado interés por razones diversas. En su estudio sobre el medievalismo romántico Elizabeth Fay señala que este interés romántico tenía que ver con un nuevo concepto de historia que se venía desarrollando hacia el siglo XIX y la importancia que se daba a la sensibilidad y a los elementos femeninos de la cultura que desembocan en un gusto por la tradición poética de los trovadores (25-26). Silvia García Alcazar habla de la importancia que en el siglo XIX se le daba a la "psicología del yo" que se buscaba en el periodo medieval en contraposición a los valores universales del clasicismo (460). Hay quienes han señalado que hoy en día el gusto popular por la Edad Media tiene que ver con la necesidad de representar mundos en los que lo fantástico tenga cabida:

si nos remitimos al universo medieval, con objeto de contrastar el pasado, se constata que lo extraordinario se da como algo objetivo -considerándose más un estado de cosas que una categoría-, entronca con lo sagrado y forma parte de una suprarrealidad. Por ello los límites entre historia, mitos y leyendas suelen quedar difuminados, ya que la importancia de lo escrito, la auctoritas, llega a legitimar la veracidad de un acontecimiento. Algunas de estas peculiaridades han sido observadas por Jacques Le Goff, quien propone los adjetivos mirabilis, magicus y miraculosus para explicar el ámbito de lo sobrenatural en el imaginario medieval (Le Goff, 1985, 13). Y 
esta misma clasificación va a ser aplicada a la narrativa juvenil, en un intento de mostrar un posible itinerario para la construcción de la competencia cultural y literaria en torno a un período clave de la historia, período que, envuelto generalmente en la bruma del tiempo y el romanticismo legendario, constituye el escenario de buena parte de las ficciones fantásticas. (Martín 194)

Para un público quizá menos juvenil, como sería el caso en la famosa serie televisiva de Juego de tronos (Game of Thrones) el interés que su medievalismo despierta ha sido entendido como la necesidad de vernos (por lo menos occidente) frente a la representación de un mundo desestabilizado y cada vez menos occidentalizado semejante al que se conoció durante el final de la edad media (Breen).

Las obras contemporáneas que se inspiran en el medievo suelen presentar una Edad Media con valores modernizados, alejada de aquello que podríamos llamar 'fidelidad histórica'. Por supuesto que no es reprobable que la ficción se inspire en un periodo o intente reproducirlo para entretener al público moderno, incluso desapegándose de la realidad histórica, pero sí me parece importante que los alumnos de una materia de literatura medieval sean capaces de conocer, hasta donde sea posible, las diferencias entre el medievo y la representación moderna de ese periodo. De hecho, hay quien han llegado a proponer que es la obligación de quienes estudian esta tradición humanística corregir los errores y confusiones que se crean con respecto a este periodo (Utz).

El curioso caso del cartel de los caballeros templarios, presunta asociación delictiva, podría utilizarse como muestra de lo anterior (Borges; Caballeros templarios (cartel)). Así, sucede que en nuestras representaciones contemporáneas del mundo medieval la ética caballeresca es malentendida a pesar de que, como afirma Utz sobre un casa paralelo, "tens of thousands of learned books and articles about medieval knighthood have had no influence on white supremacists' appropriation of allegedly chivalric virtues”. Lo mismo sucede con el papel central que jugó la religión en la visión de mundo medieval y que se manifiesta tanto en la cultura oral como en la escrita o en la producción arquitectónica y en la organización jerárquica de la sociedad. Tampoco suele dársele en la ficción medieval moderna mucha importancia a la labor de los clérigos en la transmisión de conocimiento. Durante el medievo, a lo largo y ancho de Europa se mantenía y aumentaba el conocimiento en monasterios, escuelas catedralicias y 
estudios generales o universidades. Este grupo de individuos pronto fue adquiriendo importancia en la corte de los monarcas castellanos hasta llegar a jugar un papel central durante el siglo XIII en la corte del rey Alfonso X. En la ficción popular actual estos temas difícilmente tienen cabida, pues quizá no sean lo suficientemente románticos o populares, a pesar de que son centrales para conocer el mundo medieval.

La obra del Rey Alfonso X, El Sabio, que aparece en un momento fundacional de nuestra lengua y literatura (castellano) suele no despertar la atención de los alumnos de literatura española I semestre a semestre. Usualmente son el Mio Cid, el Libro de buen amor y La Celestina los libros que más entusiasman, pero otros como las Siete Partidas o las historias de España alfonsíes suelen ser consideradas lecturas tediosas, precisamente por carecer de aquello que he venido señalando como lo interesante actualmente de la Edad Media. Lo anterior a pesar de que, en términos académicos, en esta obra se encuentra plasmada una visión de mundo peculiar del medievo castellano (Gómez 423) que tiene que ver con el desarrollo del vernáculo como medio de difusión del conocimiento y, además, a pesar de que históricamente es un episodio digno de la exitosa serie de televisión Juego de Tronos, que fue tan popular durante el 2014 y 2015. Se trata de un momento extraordinario en la historia medieval castellana en la que un monarca castellano, Alfonso X sueña con hacerse coronar Sacro Emperador Romano.

De la lectura de estos textos alfonsíes uno quisiera que los alumnos reflexionaran sobre qué hacía el rey de Castilla y León queriendo reinar a mil ochocientos kilómetros de sus tierras en Alemania en el antiguo imperio de figuras legendarias como Barbarroja, Carlomagno o Cesar Augusto; o la relación que existe entre sus obras y sus aspiraciones imperiales. Para llegar a ser emperador, es de suponerse, Alfonso debía entrar a la palestra como un hábil monarca europeo capaz de manipular soberanos y principados distantes. Esta acción requeriría ser conocedor a fondo las relaciones y las figuras políticas locales de los distintos territorios de Alemania, Holanda e Italia sobre los que habría de imperar. Además, debía convencer a siete príncipes electores alemanes de elegirlo a él por sobre Ricardo de Cornualles, labor que requeriría por su puesto, grandes sumas de dinero castellano y apoyo político en las distintas luchas de poder entre güelfos y gibelinos. Dieciocho años después de ofrecer su candidatura el trono el rey se ve obligado a renunciar a sus aspiraciones y todo su esfuerzo termina en un épico fracaso digno de olvido. 
O casi, pues intentando mostrarse a la altura del imperio, Alfonso X dedicó gran parte de su tiempo y de sus recursos económicos a la producción de una fenomenal obra literaria, histórica y científica (Gómez 643). Bajo su dirección se escribieron los enormes tomos de la General Estoria y la Estoria de España, nuevos códigos de leyes como las Siete partidas, así como una serie de obras y tratados científicos, sapienciales y literarios, muchos de ellos traducidos del árabe (181).

\section{EL JUEGO DE ROLES RT'TP}

El RTTP, reacting to the past (reacción o interacción con el pasado), como se ha dicho, es un modelo de enseñanza-aprendizaje que se basa en los juegos de roles. Profesores en cientos de universidades han implementado este sistema en sus programas con enorme éxito (Selingo 202). La dinámica usual de este modelo consiste en revivir un momento de la Historia recreando los hechos y los eventos más importantes de una situación histórica sin limitarse por ello a seguir los eventos tal cual sucedieron históricamente, sino dejando que el pasado cobre vida y el curso de la Historia sea más bien el resultado de las consecuencias de las decisiones de los propios alumnos involucrados y no de los personajes cuyos roles adoptan (Proctor 71); en otras palabras, son las habilidades, las destrezas y la participación de los estudiantes lo que habrá de determinar el curso de la Historia. En el RT'TP cada alumno de la clase ocupa un papel o un rol, cada personaje tiene un objetivo y cada sesión de clases se da siguiendo una serie de actividades que los mismos alumnos vienen deseosos a realizar para lograr sus fines privados como participantes.

Existe un amplio catálogo de juegos ya implementados con éxito, entre ellos mencionaré títulos como el Confucionismo y la crisis de sucesión del emperador Wanli en 1587; Definiendo una nación: India en la víspera de su independencia; México en la revolución y El juico de Galileo: el aristotelismo, la Nueva Cosmología y la Iglesia Católica en 1616 (Reacting, Proctor 82). En todos estos juegos de RTTP los alumnos deben adoptar la postura de su rol y tratar de reaccionar ante los eventos de la Historia siguiendo sus objetivos particulares.

\section{LA ADAPTACIÓN PARA EL ESTUDIO DE LA LITERATURA}


Durante las dos primeras semanas del mes de octubre de 2014 se realizó la adaptación de este modelo pedagógico en la materia de Literatura Española I en la Licenciatura en Literaturas Hispánicas de la Universidad de Sonora. En nuestro caso el juego fue llamado ‘ Juego de Tronos: El Fecho del Imperio' y el objetivo general del juego era que los alumnos aprendieran sobre este momento de la historia de España del siglo XIII leyendo la obra Alfonsí en su contexto histórico. También se esperaba que los alumnos ahondaran en las complejas relaciones de poder nobiliario del medievo, particularmente la disputa por el dominio del mundo entre emperadores y papas.

A cada uno de los treinta y cinco alumnos de este grupo en particular se le asignó un rol (personaje) con objetivos específicos y sugerencias en términos de estrategias que podrían implementar para lograr sus propósitos (ver Anexo 2). Entre los principales personajes o roles se encontraban los contendientes al trono: Alfonso X y Ricardo de Cornualles; los siete electores del imperio romano quienes habrían de elegir a uno de los contendientes; el Papa (agrupando los tres papas que ascendieron al trono en lo que duró la disputa), los reyes de Francia, Aragón, Navarra, Inglaterra; las ciudades de Milán, Venecia, Pisa, Ferrara, Florencia, Génova, entre otras (personajes-ciudades); Manfredo de Sicilia, Carlos de Anjou, Sancho el bravo hijo de Alfonso y algunos nobles castellanos; cardenales, arzobispos, banqueros, judíos, el emir de Granada, y el emperador bizantino. Cada uno de estos personajes tenía una misión propia que le había sido entregada en su hoja de rol (ver Anexo 2) y, en la mayoría de los casos, sus objetivos se encontraban diametralmente opuestos a los deseos y necesidades de otros roles de personajes del juego, haciendo necesaria la competencia entre jugadores.

Las sesiones de clase solían ser caóticas para quien no entendía qué estaba en proceso y, ciertamente, al inicio algunos estudiantes no comprendían bien qué debían hacer o qué estaba sucediendo. Los teóricos y practicantes de este modelo sugieren un periodo de dos o tres días de instrucción y adaptación como parte del juego, pues es natural que algunos de los participantes que no estén acostumbrados a este tipo de actividades se sientan confundidos (Proctor 31). Puesto que en nuestro caso cada sesión de clases culminaba con el voto de los siete electores a favor de uno de los dos contendientes al trono (Alfonso o Ricardo), y puesto que cada voto equivalía a una cantidad de cien mil marcos (una cantidad elevada dada la economía del juego), pronto los alumnos comenzaron a darse cuenta que debían organizarse e 
integrar a otros participantes para buscar lograr sus objetivos particulares antes de que fuera demasiado tarde.

Si bien la repartición de dinero por cada voto de los electores se desapega de la facticidad histórica, pues en realidad ninguno de los dos recibía dinero a cambio de votos a favor, dentro del juego este mecanismo permitió mantener a los alumnos en constante actividad diplomática y de negociación. Hacer esto fue un gran acierto, y además, según los expertos del RTTP, los juegos no deben ser rígidos en su apego a la historia que se conviertan en meras representaciones teatrales (Proctor 71). Durante la última sesión del juego se llevó a cabo una votación final para elegir al sacro emperador romano. En nuestro caso terminó como ganador Ricardo de Cornualles y pasó a ocupar el trono al Sacro Imperio Romano.

El juego tenía provisión para resolver conflictos entre las distintas facciones mediante la guerra. Para ello cada parte debía apostar una cantidad de recursos. Los recursos se adquirían mediante un examen diario que se hacía sobre cierta parte de la obra de Alfonso X, así como con el pago o retención de diezmos, otras guerras o negociaciones internas. El papa tenía poderes de excomunión y, puesto que esto excluía a los excomulgados de participar en actividades relacionadas con la adquisición de recursos, se venían obligados a negociar directamente con el papa para volver al juego o, como también sucedió en nuestro caso, buscar la manera de elevar a otro de los cardenales al papado, uno que fuera su aliado.

Los alumnos podían negociar durante y fuera de la clase. Es común entre las experiencias de quienes participan en estas dinámicas que la tarea se convierta en una obsesión (Salingo 202). Cuenta uno de los participantes de nuestro juego que mientras él se encontraba en una reunión entre amigos durante el fin de semana recibió una llamada de otro de los participantes del juego. Sin reflexionar sobre el efecto que sus comentarios causaban entre sus amigos que lo escuchaban, el alumno comenzó a planear con su interlocutor declararle la guerra al rey de Castilla y buscar los medios para evitar la excomunión puesta por el papa a quien tal hiciese. Puesto que hacía estos comentarios en un tono serio y calculador, cuando terminó su llamada telefónica se encontró con la mirada cuestionadora de sus amigos que una vez que supieron que se trataba de un juego de roles no tardaron en decirle que era un "freak" o un raro. El ejemplo anterior no representa un caso único. Varios alumnos comentaron vivencias similares e incluso yo mismo me hallé dando respuesta a través de medios 
electrónicos a consultas urgentes sobre estrategias de parte de alumnos a altas horas de la madrugada.

Si bien el juego resultó un excelente medio para involucrar a los estudiantes en el mundo Alfonsí, admito que el juego tuvo ciertas fallas. Es imposible prever todos los cauces por los que pueden fluir los pensamientos y las emociones humanas y en nuestro caso en particular sentí que fue necesario acortar la interacción al final, pues la dinámica comenzaba a tener peso emocional entre algunos. Un comentario que escuché de varios alumnos era que la dinámica los estaba dividiendo, pues en algunos casos sus amigos más cercanos eran sus rivales en el juego y los dos mundos comenzaban a mezclarse. Nada imprevisto: en sus manuales los teóricos y practicantes del RTTP han mencionado este problema como un fenómeno común. Un profesor declaró que en uno de sus juegos, "todo en la superficie era cortesía, pero que por abajo del agua se estaban dando puñaladas traperas" (Salingo 203). Para minimizar este problema se recomienda iniciar las sesiones con un acto que Proctor llama "círculo mágico" (26), una actividad que enmarque las acciones del juego y ponga las interacciones en perspectiva. En nuestro juego iniciábamos con un breve video que edité tomado del promocional de la serie de Juego de Tronos; en retrospectiva me queda claro que hubiera sido más significativo haber iniciado las sesiones con un acto más evidente, como recitando un $T e$ Deum o una cantiga de Santa María alfoní previamente memorizada por todos durante las primeras sesiones del juego.

\section{LA JUSTIFICACIÓN}

Una preocupación que tenía en mente mientras planeaba la mecánica del juego se relacionaba con la pertinencia de recurrir a este tipo de ejercicios con alumnos que, por lo menos en teoría, no necesitan incentivos para leer, pues son alumnos de literatura. Quizá la pregunta no podía ser respondida en su momento, pero terminado el juego de roles me parece pertinente reflexionar sobre estas preguntas: ¿Realmente representó esta dinámica el aprovechamiento óptimo del tiempo para el estudio de la literatura? ¿El aprendizaje obtenido según las evaluaciones fue el deseado?

Definitivamente. En primer lugar el RTTP facilita la comprensión del momento histórico cuando éste es importante para conocer las complejidades de un fenómeno literario 
en particular. En el caso del estudio de la literatura española medieval el contexto histórico y cultural es parte esencial del conocimiento de los textos; sin embargo, mediante la cátedra tradicional el trasfondo político, social y económico no suele ser sino una nota al pie de página sobre la obra. Sin conocimiento del contexto histórico del periodo alfonsí en la historia del desarrollo de la prosa en castellano, los textos de historia o de leyes o de ciencia, que representaron un momento cúspide en la formación de nuestra lengua y literatura, no dejan de ser para el alumno meras trivialidades de la época carentes de significancia. El empleo del RTTP permite contextualizar la literatura tanto como contextualizar la historia en la literatura.

Además del aprendizaje del contexto histórico y la lectura del texto, que es lo más importante, resaltaría como lo más inmediato en segunda instancia que este procedimiento del juego de roles desarrolla habilidades deseables en los futuros profesionistas, y aunque no me refiero a "puñaladas traperas" como las que posiblemente se dieron en clase durante la actividad, sí me parece importante que también se tome en cuenta la necesidad de aprender a interactuar con quienes tienen objetivos contrarios a uno en vida real. Resaltaría el impacto que podría tener en impulsar la capacidad de expresión oral y escrita, la habilidad de argumentación y el desarrollar su aptitud de convencimiento, así como la planeación, el trabajo en equipo y el pensamiento crítico.

El modelo del RTTP permite dinámicas que desarrollan una serie de actitudes y valores en los estudiantes, como la creatividad, flexibilidad, adaptación, dedicación, decisión, determinación y asertividad. Muchos de estos atributos los deseamos como parte de la formación humanística de nuestros alumnos, pero en la práctica son ajenos a aquello que hacemos con los textos literarios o, por lo menos -lo que me parece más cierto-, son competencias que dejamos que el alumno desarrolle de manera indirecta y solitaria. Mediante este tipo de actividades los alumnos pueden leer y analizar el texto a la vez que descubren en sí mismos habilidades adicionales que quizá de otra manera no explorarían por falta de tiempo durante su carrera universitaria. (ver video RTTP: Fecho del imperio en youtube. https://www.youtube.com/watch?v=clMknmzvIzU)

\section{LOS RESULTADOS}


Como parte de las actividades del juego, los alumnos debieron entregar un reporte escrito sobre sus estrategias, logros, dificultades y resultados finales. De hecho, de esto dependía su calificación. Uno de los alumnos que menos participó (y su falta de participación fue una excepción atribuible a su edad, pues se trata de un profesionista de carácter serio de unos cincuenta años de edad) comentó lo siguiente: "Fue interesante ver cómo todos los compañeros se identificaron con su personaje y lucharon hasta el final para coronar a su favorito". Otro estudiante, un alumno que no asistía regularmente a clases, pero que durante el juego fue un asiduo participante comentó en su reporte: 'Yo, Rey de Navarra, gozando de toda mi soberanía, siempre supe que mi alanza con los franceses era uno de mis objetivos principales, pero por motivos personales de enriquecimiento, decidí unirme a Manfredo de Sicilia en contra del Papa. . . [sin embargo] perdí más del cincuenta por ciento de mi fortuna y quedé casi en la ruina”.

En la bitácora del Arzobispo Gerardo de Maguncia leemos: “01 de octubre. Ricardo nos prometió muchos derechos y se ve que es un hombre con mucha riqueza e influencias. [. . . ] 09 octubre. ¡Todo es un caos! Derrocaron al papa y ahora tenemos uno nuevo llamado Gregorio X. Todo está muy inestable, así que me vi en la necesidad de firmar un tratado [. . .] para asegurar mi protección”. Alfonso X, uno de los dos contendientes al trono escribió: "Me di cuenta aquí de lo fácil que es manipular a la gente con unos cuantos miles de marcos que yo ganaba gracias a ellos y ni siquiera se daban cuenta". Y puesto que no resultó ganador, su reporte termina diciendo "Y ya como nota personal fueron dos semanas estresantes, pero divertidas. Me hubiera gustado mucho ver correr sangre y que todos los que me traicionaron sufrieran, pero aprendí bastante y fue muy refrescante hacer algo tan nuevo”.

Me parece que los reportes escritos, de donde se tomaron las citas anteriores muestran el grado de compromiso de los estudiantes con la dinámica del juego (se incluye un fragmento de un reporte en el Anexo 1 que permite comprender la dinámica del juego a la vez que resume lo sucedido). Durante las dos semanas que duró la actividad, veía a los estudiantes decididos a comprender su papel en la historia y la de sus enemigos y aliados para lograr el éxito. Algunos alumnos releyeron el texto alfonsí para buscar inspiración, otros fueron más allá e investigaron a profundidad obras históricas sobre el periodo para asegurar mejor el éxito de su estrategia y no dejarse vencer por enemigos desconocidos. 
Se anexa también a este documento (Anexo 3) una tabla en la que se muestra el resultado de una evaluación para medir el grado de retención del conocimiento adquirido sobre el tema. La tabla muestra las calificaciones obtenidas por este grupo experimental (2014) en un examen sorpresa aplicado justamente un año después (octubre 2015). Es observable que, en comparación con el resultado obtenido en el mismo examen por el grupo de control (2015) que acababa de estudiar el mismo contenido sobre la prosa Alfonsí pero sin la dinámica del RTTP, el nivel de retención de la información es extraordinario según los parámetros de la curva del olvido (Curva del olvido) que suponen una pérdida de la retención de hasta 90\% después de un año de no repasar esa información.

\section{CONCLUSIONES}

El 'Juego de tronos: Fecho del imperio' es solo una manera de adaptar el RTTP a la literatura estudiando el contexto histórico y cultural. También podría utilizarse para estudiar las obras literarias mismas. Se pudiera, por ejemplo, recrear el juicio legal de 1857 sobre cuestiones de moral de la novela Madame Bovary para debatir los méritos artísticos de la obra y el problema del contenido en la literatura. También se podría hacer un análisis en una actividad similar con las Cartas de relación de Hernán Cortés llevándolo a juicio para determinar si actuó bien o mal según los valores morales y la política de la época, pues se recordará que las Cartas fueron prohibidas y condenadas al fuego en 1527. Este juego podría incluir lecturas de otras crónicas de Indias, de El príncipe de Maquiavelo, de Libros de caballerías como el Floriseo (1516), documentos históricos sobre el gobierno de las Indias, etc. En estos casos y en muchos más que puedan imaginarse, los alumnos tendrían que leer con detenimiento la obra y empaparse profundamente del contexto histórico, social, artístico a la vez que elaboran estrategias retóricas sutiles qué emplear durante la interacción social. Las actividades requerirían participar en debates, presentaciones orales y escritas y otras acciones similares.

Después de mi experiencia, estoy convencido de que el RTTP adaptado para su uso en el estudio de la literatura podría ser una herramienta pedagógica extraordinaria para ayudar a los estudiantes a leer, comprender y evaluar textos literarios, al mismo tiempo que los impulsa a desarrollar competencias adicionales que rara vez se toman en cuenta en su formación 
académica y que, sin embargo, sabemos que son necesarias en su desarrollo como personas y profesionistas.

\section{REFERENCIAS BIBLIOGRÁFICAS}

Caballeros Templarios (cártel). Wikipedia, La enciclopedia libre. 4 oct 2015, 16:55 UTC. 7 oct 2015, 00:59

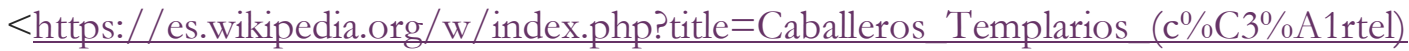

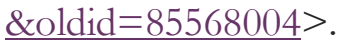

Barnard College. "Instructor Resources". Reacting to the Past. 17 de febrero 2015.

https://reacting.barnard.edu/curriculum/published-games.

Borges, Tomás "El Profe del Narco, líder de los Caballeros Templarios" Los Angeles Press. 2 de octubre de 2013. 5 de octubre de 2015. http://www.losangelespress.org/el-profe-delnarco-lider-de-los-caballeros-templarios/.

Breen, Benjamin. "Why 'Game of Thrones' Isn't Medieval-and Why That Matters”. Pacific Standard. 12 de junio de 2014. Consultado 6 de octubre de 2015. http://www.psmag.com/books-and-culture/game-thrones-isnt-medieval-matters$\underline{83288}$.

Cuddon, John. The Penguin Dictionary of Literary Terms and Literary Theory. New York: Penguin, 1998.

Curva del olvido. Wikipedia, La enciclopedia libre. 23 jun 2014, 02:45 UTC. 9 oct 2015, 15:50 $<$ https://es.wikipedia.org/w/index.php?title=Curva_del_olvido\&oldid=75185368>

Fay, Elizabeth A. Romantic Medievalism. History and the Romantic Literary Ideal. New York: Palgrave, 2002.

García Alcázar, Silvia. "El medievalismo decimonónico como base de la restauración monumental romántica en España" Actas del Séptimo Congreso Nacional de Historia de la Construcción. Santiago de Compostela. (2011): 459-468. Consultado 5 de octubre de 2015. http:// www.sedhc.es/biblioteca/actas/CNHC 7\%20\%2847\%29.pdf.

Gautier, Théophile. Mademoiselle de Maupin. Barelona: Random House Mondadori, 2010. 
Gerrard, Christopher. Medieval Archaeology:Understanding Traditions and Contemporary Approaches. New York: Routledge, 2002.

Gómez Redondo, Fernando. Historia de la prosa medieval castellana I. La creación del discurso prosístico: el entramado cortesano. Madrid: Ediciones Cátedra, 1998.

Proctor, Nicolas W. Reacting to the Past Game Designer's Handbook. $3^{\mathrm{a}}$ Ed. Des Moines: Simpson College, 2013.

Martín Rogero, Nieves. "Ficción literaria y educación. Lo fantástico medieval en la narrativa juvenil”. Didáctica. Lengua y Literatura. 20 (2008): 191-209.

Selingo, Jeffrey J. College Unbound: The Future of Higher Education and What It Means for Students. New York: New Harvest, 2013. Kindle Edition.

Utz, Richard. "Don't be Snobs, Medievalists". The Chronicle of Higher Education. August 24, 2015. Consultado el 5 de octubre de 2015. http://chronicle.com/article/Dont-BeSnobs-Medievalists/232539/. 


\section{ANEXO 1.}

\section{Reporte del fecho del Imperio}

\section{Personaje: Papa (Alfonso IV)}

“30 de septiembre:

Nos reunimos por primera vez todas las facciones correspondientes al Sacro Imperio Romano. Examinando inquietamente con quién podría hacerme aliado, me vi en la tarea de hacer la colecta de diezmos con el fin de entablar conversación con cada uno de mis fieles siervos.

Parece ser que no les gusta el costo de los diezmos; les he explicado cuál es su función y de cómo ayudan a la iglesia, pero no les gusta la manera en que se emplea el dinero que se recauda. Parece ser que le tienen miedo a la guerra y creen que sus aportaciones no les traerán ningún beneficio. ¡Qué inconscientes!

1 octubre:

Después de las charlas que tuve con los 'encargados' de las diferentes facciones, si se puede decir así, me di cuenta de que tienen muchas inconformidades con las aportaciones que hacen a la iglesia, recibí varias quejas y peticiones. El rey Manfredo fue uno de los más inconformes, acordamos una disminución de sus diezmos a cambio de su lealtad.

No confío en él.

Hablé con los dos candidatos al Sacro Imperio Romano, parece ser que ambos se creen merecedores del trono del imperio.

2 de octubre:

Antes de la recolección de diezmos, un joven vino a mí en busca de salvación. Le ofrecí ser mi tesorero, a lo que él encantado y emocionado me pidió también tener la oportunidad de recolectar los diezmos, lo que consiste en no sólo recolectar el diezmo, sino también las quejas y sugerencias diarias. 
Ante el mundo se han develado las intenciones de cada candidato. Ambos ofrecen buenos servicios para la iglesia, pero quieren interponerse muy a fondo, así que tengo que llegar a un acuerdo con cada uno o, al menos, hacerme de aliados para detenerlos en caso de que quieran suplantar a otro en el sagrado trono de San Pedro.

6 de octubre:

Hoy he hablado con Ricardo de Cornualles, hemos acordado una forma de alianza. Desconfío un poco de él ya que no parecen haberle gustado mis demandas. Hasta que la gente esté tomando posturas y comiencen a develar sus objetivos, no procederé a ningún acuerdo, por el momento he llegado a un muy buen trato de paz con el rey Otokar, Sancho IV y el arzobispo de Toledo.

Excomulgué al duque de Sajonia y al rey de Navarra por sus adeudos, parece ser que ambos están metidos en una conspiración para poner a alguien de su conveniencia como el representante de San Pedro; sin embargo, como no tengo ninguna evidencia de esto, por una módica cantidad de marcos los dejaré volver a comulgar.

Mucho antes de comenzar con la recolección de diezmos, la gente vino a mi, no por ayuda, sino para darme más quejas. Me di cuenta de que había perdido un poco de mi rebaño y lo peor es que fueron guiados al mal por un banquero malévolo que se infiltró hasta lo más íntimo de las partes en candidatura.

7 de octubre:

Hoy se ha presentado a la corte el duque de Sajonia, me ha pagado sus adeudos, por lo que lo he dejado entrar al rebaño nuevamente. Espero poder conseguir un poco de su apoyo para evitar conflictos con la iglesia y la nueva forma institucional del gobierno monárquico.

Ricardo de Cornualles ha traicionado mi confianza dejándose influenciar por la voluntad del banquero, así que tengo que hablar rápido con él para saber en qué condiciones se encuentra nuestro tratado de paz. He hablado con el rey Otokar y con Manfredo de Sicilia, ambos 
parecen también haberse dejado influir por las palabras de este banquero que se está volviendo alguien muy 'persuasivo' en la corte.

Además de esto, el rey Otokar y el arzobispo Conrado de Colonia, disputaron mediante una brava guerra por el territorio y las posiciones del otro, el Arzobispo ganó la guerra sin mucha demora. Parece que el rey Otokar ha quedado en bancarrota y se ha aliado con Ricardo de Cornualles en busca de protección y apoyo económico.

8 de octubre:

Hoy la gente me ha desconocido como su papa y, además de eso, se ha desatado un zafarrancho con la reunión, todos pelearon por una porción de poder e inmersos en la confusión unos querían pelear con aliados y los reyes presentaron demandas contra la iglesia, las cuales no tenían ningún sentido pues ya les he dado una disminución a sus diezmos; al parecer Ricardo de Cornualles y el banquero se han aliado para sacarme del trono de San Pedro y así tomar la iglesia para su conveniencia, lo cual considero un ultraje y por lo tanto todo aliado de alguno de ellos ha quedado excomulgado.

9 de octubre:

La estrategia de Ricardo de Cornualles y el banquero ha sido por fin tomada en acción y los cardenales han votado por sacarme del sacro trono de San Pedro, me han quitado y en mi lugar pusieron al cardenal de Rambouxchauyene, el nuevo papa Gregorio X.

Las cosas se han salido de mis manos y todos hemos entrado en conflicto por la mala organización de nuestra alianza. Alfonso X y yo no hemos podido hacer estrategias viables que operen bajo los estatutos de la corte, hemos perdido aliados y esto nos podría costar la guerra que se avecina con Manfredo de Sicilia.

Ya en guerra, Manfredo y yo hemos combatido desenfrenadamente durante un lapso de treinta y un batallas. Inicié con una inconcebible desventaja sobre Manfredo de un millón a cinco mil, pero Manfredo parece llevado por una magia divina que no me permite interceptarlo, me ha derrotado en veinte de treinta batallas. 
He sido vencido por Manfredo de Sicilia, he quedado en la bancarrota y adeudado, además de que por si fuera poco me han olvidado mis siervos en todo el mundo.

12 de octubre:

El día de hoy se ha proclamado a Ricardo de Cornualles como el nuevo emperador del Sacro Imperio Romano.

Y yo expulsado de la iglesia lo miro desde lejos.” 


\title{
ANEXO 2.
}

\section{Instrucciones para el rol de Alfonso X}

\author{
REY ALFONSO X DE LEON Y CASTILLA
}

OBJETIVO PRIMARIO: SER ELEGIDO SANTO EMPERADOR ROMANO

OBJETIVO SECUNDARIO: SER CONSIDERADO EMPERADOR DE LOS GODOS

Tu padre Fernando III, el santo, te dejó como herencia los reinos de Castilla y León. Tu madre Beatriz de Suabia, pertenece a la familia de los Staufen, por lo que cuenta entre sus parientes a dos famosos emperadores del Sacro Imperio Romano: Federico I, Barbarroja y Federico II, alias, el asombro del mundo. Ambos fueron considerados en su tiempo grandes emperadores, guerreros y diplomáticos. No temieron oponerse al poder papal ni aunque les costara el cielo, pues ambos sufrieron la excomunión. Ahora te toca a ti heredar su imperio y tratar de imitarlos en su importancia terrenal.

Deberás rodearte de aquellos reinos y señoríos que puedan apoyarte en tu candidatura. Las ciudades estado italianas como Pisa y Venecia, entre muchas otras, suelen estar del lado de los emperadores en su pugna contra el Papa. Asimismo, recuerda que tu esposa Violante es hermana del rey de Aragón, de modo que éste podría serte un buen aliado si sabes negociar bien con él. Trata de mantener buenas relaciones con los nobles de tu propio reino. Recuerda que muchos reyes han fracasado al ignorar a su propio pueblo y parientes cercanos. Si bien éstos están dispuestos a serte leales, no desean que se les retiren sus antiguos privilegios y fueros. Sabes bien que estos privilegios son cosa del pasado y que no pueden por mantenerse siempre. Por lo tanto, trata de elaborar una estrategia que te permita disminuir sus privilegios sin que te retiren la lealtad.

Riqueza acumulada 150,000 marcos

Ingreso diario 5000 marcos

\section{ANEXO 3}

Guerra, doi: https://doi.org/10.36799/el.v1i1.28 Volumen 1, Número 1, Año 2016, ISSN: 2448-5942 


\section{Instrucciones para el rol de El papa}

RTTP PAPA (ALEJANDRO IV, CLEMENTE IV, GREGORIO X)

\section{PAPA}

Si bien tu posición eclesiástica te ubica como uno de los principales poderes europeos, tu poder secular no se extiende más allá de unas cuantas ciudades alrededor de Roma. Tu influencia, sin embargo, es extensa. Todos los reinos europeos deben enviarte los diezmos de sus iglesias a través de sus líderes eclesiásticos; el Sacro Emperador Romano debe ser ungido por ti para entrar en vigor; muchos reyes, lo exige su tradición, deben ser confirmados por tu mano; tienes poder de atar y desatar matrimonios, promesas, juramentos, etc. Los emperadores como Barbarroja y Federico II siempre fueron un problema para el papado, pues en muchos casos sus políticas debilitaban el poder papal. No quieres que se elija un nuevo Barbarroja.

Objetivo Primario: Evitar la elección de un emperador.

Objetivo secundario: Intervenir en la política para conseguir la elección de un Emperador débil y sirvo fiel de la Iglesia Católica. Alguien a quien puedas considerar tu mano derecha y que haga todo lo que le pidas.

El gran "As" debajo de la manga que puedes utilizar es la excomunión. Úsala con moderación, pero no temas emplearlo para evitar que las cosas se salgan de debajo de tu control

Riqueza Acumulada 200,000 marcos

Ingresos diarios 0 marcos (Deberás asegurarte de que se te den los diezmos) 


\section{ANEXO 4}

\section{Resultados de un examen sorpresa aplicado a los grupos de Literatura Española I}

El grupo 2015 (grupo de control) estudió la prosa alfonsí dos semanas antes del examen sorpresa obteniendo como resultado un promedio de 69. El grupo 2014 (grupo experimental) obtuvo como resultado de la aplicación de ese mismo examen sorpresa justamente un año después de haber cubierto el material un promedio de 67. A continuación se ofrecen los resultados específicos obtenidos.

\begin{tabular}{|c|c|}
\hline $\begin{array}{c}\text { Grupo de control } \\
2015\end{array}$ & $\begin{array}{c}\text { Grupo } \\
\text { Experimental } 2014\end{array}$ \\
\hline 60 & 90 \\
\hline 60 & 20 \\
\hline 40 & 80 \\
\hline 100 & 100 \\
\hline 80 & 60 \\
\hline 60 & 80 \\
\hline 80 & 60 \\
\hline 100 & 80 \\
\hline 40 & 60 \\
\hline 100 & 20 \\
\hline 60 & 40 \\
\hline 60 & 60 \\
\hline 100 & 60 \\
\hline 60 & 100 \\
\hline 60 & 80 \\
\hline 40 & 80 \\
\hline 68.75 & 66.875 \\
\hline
\end{tabular}

